УДК 637.5:619:615.9(470.333)

ОПТИМИЗАЦИЯ ПРИМЕНЕНИЯ ФЕРРОЦИНСОДЕРЖАЩИХ ПРЕПАРАТОВ ДЛЯ ПРОИЗВОДСТВА

НА РАДИОАКТИВНО ЗАГРЯЗНЕННЫХ ТЕРРИТОРИЯХ БРЯНСКОЙ ОБЛАСТИ МЯСА ГОВЯДИНЫ, СООТВЕТСТВУЮЩЕГО САНИТАРНО-ГИГИЕНИЧЕСКИМ НОРМАТИВАМ

Исамов Н.Н., Панов А.В., Цыгвинцев П.Н., Губарева О.С.

ФГБНУ «Всероссийский научно-исследовательский институт радиологии и агроэкологии», Обнинск, е-mail: nizomis@yandex.ru

Оценка результатов содержания ${ }^{137} \mathrm{Cs}$ в продукции животноводства и кормопроизводства сельскохозяйственных предприятий пяти юго-западных районов Брянской области выявила хозяйства, в которых наблюдается превышение радиологических нормативов в производимой сельскохозяйственной продукции. В ходе исследований установили, что плотность радиоактивного загрязнения сенокосов и пастбищ с высокой степенью достоверности $\left(\mathrm{R}^{2}>0,99\right)$ определяет как уровень загрязнения рациона, так и содержание ${ }^{137} \mathrm{Cs}$ в мясе КРС. Предложена оптимизированная стратегия применения ферроцинсодержащих препаратов (ФСП) для производства на радиоактивно загрязненных территориях мяса говядины, соответствующего санитарно-гигиеническим нормативам. Проведен расчет объемов применения сорбента в пяти юго-западных районах Брянской области, а также дана оценка экономической эффективности его применения в смеси с комбикормом. Наибольшую потребность в объемах применения ФСП в условиях радиоактивного загрязнения кормовых угодий выявили для хозяйств Новозыбковского района, а наименьшую (в 4,3 раза) для сельхозпредприятий Злынковского района. Определяющими факторами явились плотность загрязнения кормовых угодий и численность продуктивного поголовья скота района. Полученные в ходе исследования результаты дают возможность корректировать стратегию реабилитации сферы сельскохозяйственного производства (мясное животноводство) на радиоактивно загрязненных, вследствие аварии на ЧАЭС, территориях.

Ключевые слова: крупный рогатый скот на откорме, мясо, цезий-137, прижизненная дозиметрия, сорбент, ферроцин, авария на ЧАЭС, радиационый контроль, корма

\title{
OPTIMIZATION OF APPLICATION OF FERROCINE CONTAINING PREPARATIONS FOR BEEF MEAT PRODUCTION MEETING SANITARY AND HYGIENIC STANDARDS ON RADIOACTIVELY CONTAMINATED TERRITORIES OF BRYANSK REGION
}

\author{
Isamov N.N., Panov A.V., Tsygvintsev P.N., Gubareva O.S. \\ Russian Institute of Radiology and Agroecology, Obninsk, e-mail: nizomis@yandex.ru
}

\begin{abstract}
Assessment of content of ${ }^{137} \mathrm{Cs}$ in livestock and fodder products of agricultural enterprises of five southwestern districts of Bryansk region showed up the farms where there is an exceeding of radiological standards for agricultural production. During the investigations it was established that radioactive contamination density of haylands and pastures determines both the level of diet contamination and content of ${ }^{137} \mathrm{Cs}$ in cattle meat with high reliability degree $\left(\mathrm{R}^{2}>0,99\right)$. Optimization of application of ferrocine containing preparations $(\mathrm{FCP})$ for beef meat production meeting sanitary and hygienic standards on radioactively contaminated territories of Bryansk region was offered. The calculation of the amount for sorbent application in five south-western districts of Bryansk region was performed. Also the estimation of economic effectiveness of its application combined with compound feed is given in the article. The highest need of FCP application under the conditions of radioactive contamination of forage lands was defined for the enterprises in Novozybkovsky district, and the lowest one (4.3 times lower) for the enterprises in Zlynkovsky district. The determinative factors were contamination density of forage lands and amount of productive livestock of the district. The results obtained during the investigations allow to correct the strategy of recovery of agricultural production (beef husbandry) on territories radioactively contaminated due to the Chernobyl accident.
\end{abstract}

Keywords: cattle fattening, meat, cesium-137, lifetime dosimetry, sorbent, ferrocin, Chernobyl accident, radiation control, feed

Авария на Чернобыльской АЭС явилась крупнейшей в истории ядерной энергетики катастрофой, приведшей к широкомасштабному загрязнению ${ }^{137} \mathrm{Cs}$ сельскохозяйственных угодий на территории Российской Федерации. В результате аварии на ЧАЭС наибольшему радиоактивному загрязнению подверглись шесть юго-западных районов Брянской области, три района Калужской области и по одному району в Орловской и Тульской областях [1]. В ходе комплексного проведения защитных и реабилитационных мероприятий в этих районах произошло существенное оздоровление радиационной ситуации $[1,2]$. Однако, несмотря на то, что после аварии на ЧАЭС прошло более 30 лет, в наиболее пострадавших пяти юго-западных районах Брянской области до настоящего времени не удалось обеспечить производство сельскохозяйственной продукции, 
соответствующей нормативам в полном объеме [3]. Анализ данных радиационного контроля, проводимого Центром химизации и сельскохозяйственной радиологии «Брянский» и ветеринарно-радиологическими подразделениями Россельхознадзора, показал, что в 17 коллективных хозяйствах без проведения реабилитационных мероприятий невозможно получение продукции кормопроизводства и животноводства, соответствующей нормативам. В 11 хозяйствах превышение санитарно-гигиенических нормативов ВП 13.5.13/06-01 и СанПиН [4] будет носить долговременный характер вплоть до 2025-2030 гг. [3]. Основную проблему представляет загрязнение кормов, содержание ${ }^{137} \mathrm{Cs}$ в которых превышает ветеринарные допустимые уровни в 1,9-3,7 раза $[5,6]$. Высокое содержание ${ }^{137} \mathrm{Cs}$ в кормах определяет превышение гигиенических нормативов в продукции животноводства мясо и мясная продукция - в 5-8\% проб. В то же время многолетний опыт ведения животноводства на радиоактивно загрязненных территориях показал, что применение сорбентов из класса ферроцинсодержащих препаратов (ФСП - ферроцин, бифеж, болюсы и брикеты соли-лизунца) способствовало получению нормативно «чистой» продукции животноводства [7-9]. В современных условиях, несмотря на устойчивую тенденцию снижения доли загрязненной продукции и стабилизацию радиационной ситуации в сельском хозяйстве, проведение регулярного радиологического контроля и применение ферроцинсодержащих препаратов остается актуальным по сей день.

Вышеуказанные обстоятельства свидетельствуют о необходимости дальнейшего наблюдения за изменением радиационной обстановки на наиболее радиоактивно загрязненных территориях и оценки потребности в адресном проведении защитных мероприятий в мясном скотоводстве.

Целью работы являлась разработка оптимизированной стратегии применения ФСП для производства на радиоактивно загрязненных территориях Брянской области мяса говядины, соответствующего санитарно-гигиеническим нормативам.

Для реализации поставленной цели провели расчет объемов применения ФСП в пяти юго-западных районах Брянской области, а также представили оценку экономической эффективности применения смеси комбикорма с ферроцинсодержащими препаратами.

\section{Материалы и методы исследования}

Для оценки современной радиоэкологической обстановки в пяти юго-западных районах Брянской области проведен сбор, обобщение и анализ данных по плотности загрязнения кормовых угодий и основных компонентов рациона продуктивных животных, а также сведения о поголовье крупного рогатого скота в каждом хозяйстве и загрязнении ${ }^{137} \mathrm{Cs}$ мяса, производящегося в хозяйствах этих районов. Для этого использовалась информация, полученная от Центра химизации и сельскохозяйственной радиологии «Брянский» и ветеринарных радиологических лабораторий Россельхознадзора, осуществляющих плановый мониторинг сельскохозяйственной продукции в Гордеевском, Злынковском, Клинцовском, Красногорском и Новозыбковском районах Брянской области.

Для разработки оптимальной стратегии, применение которой обеспечит получение нормативно чистой сельскохозяйственной продукции в сельскохозяйственных предприятиях, ведущих хозяйственную деятельность на радиоактивно загрязненных территориях при минимальных дополнительных затратах, необходима оценка экономической эффективности технологий, направленных на снижение накопления радионуклидов в продукции.

Одной из наиболее эффективных контрмер, обеспечивающей гарантированное производство продукции животноводства, отвечающей существующим нормативам, является применение специальных ветеринарных средств на основе сорбентов для снижения поступления радиоцезия из рационов животных в мясо. Ферроцин - специфический сорбент, образующий с ${ }^{137} \mathrm{Cs}$ при поступлении в желудочнокишечный тракт животных нерастворимое комплексное соединение, которое с фекалиями выводится из организма. Тем самым предотвращается всасывание радионуклида через слизистую кишечника в кровь. Для животных препарат не оказывает отрицательного влияния на физиологическое состояние организма.

Предложенная стратегия применения ФСП предусматривает дополнительное включение в основной рацион продуктивных животных смеси комбикорма с ФСП в зависимости от уровня загрязнения кормовых угодий (сенокосы, пастбища).

Разработанная стратегия позволяет оценить объемы и экономическую эффективность применения смеси комбикорма с ФСП для производства на радиоактивно загрязненных территориях Брянской области мяса, соответствующего санитарно-гигиеническим нормативам.

Данные обрабатывали с применением пакета прикладных программ Microsoft Excel 2003.

\section{Результаты исследования и их обсуждение}

В результате исследований собраны, обобщены и проанализированы эмпирические данные о загрязнении ${ }^{137} \mathrm{Cs}$ кормовых угодий и производимого в хозяйствах пяти юго-западных районов Брянской области мяса (говядина). Оценены необходимые объемы применения смеси комбикорма с ферроцинсодержащими препаратами для поголовья КРС в хозяйствах пяти юго-западных районов Брянской области. Показано, что для обеспечения производства мяса в юго-западных районах Брянской области, соответствующего нормативу, периодически с января по ноябрь в 13-28 сельскохозяйственных предприятиях с откормочным 
поголовьем КРС от 0,7 до 5,5 тыс. голов необходимо применять сорбенты, связывающие ${ }^{137} \mathrm{Cs}$.

Следует отметить, что в исследуемый период в указанных районах животноводство велось в 58 сельскохозяйственном предприятии (табл. 1). Общая численность КРС на откорме и нагуле в этих хозяйствах составила 13,5 тыс. гол., причем наибольшее поголовье отмечено в Клинцовском районе (5,5 тыс. гол.), а минимальное в Злынковском районе (0,7 тыс. гол.).

Поскольку погрешность измерения радиометрической аппаратуры достигает $30 \%$, при сравнительном анализе мониторинговых данных с нормативами, на основе консервативного подхода, было принято, что если полученное значение содержания ${ }^{137} \mathrm{Cs}$ в продукции составляет более $70 \%$ от норматива, то он может быть превышен, т.е. существует риск несоответствия производимой продукции установленным нормам.

Обоснованием для применения смеси комбикормов ферроцинсодержащих препаратов в животноводстве является превыше- ние уровней СанПиН по содержанию ${ }^{137} \mathrm{Cs}$ в молоке и мясе КРС. Накопление и выведение радионуклида организмом животного зависит от многих факторов, но определяющим является уровень загрязнения суточного рациона. Использование кормов с различной концентрацией радионуклида позволяет в разных хозяйствах в определенной мере регулировать степень радиоактивного загрязнения производимого мяса говядины. Однако такой способ возможен при хорошо развитой кормовой базе, а в целом как степень радиоактивного загрязнения рациона, так и продукции животноводства будет определяться плотностью радиоактивного загрязнения сенокосов и пастбищ. Обобщая данные радиологических показателей в хозяйствах четырех районов Брянской области (Гордеевский, Красногорский, Новозыбковский Клинцовский), можно констатировать, что плотность радиоактивного загрязнения сенокосов и пастбищ с высокой степенью достоверности $\left(\mathrm{R}^{2}>0,99\right)$ определяет как уровень загрязнения рациона, так и содержание ${ }^{137} \mathrm{Cs}$ в мясе КРC (рисунок).

Таблица 1

Объемы радиологического мониторинга продукции молочного животноводства в хозяйствах пяти юго-западных районов Брянской области

\begin{tabular}{|c|c|c|c|}
\hline Район & Число хозяйств & $\begin{array}{c}\text { Поголовье КРС на откорме } \\
\text { и нагуле }\end{array}$ & $\begin{array}{c}\text { Число измерений содержания }{ }^{137} \mathrm{Cs} \\
\text { в мясе }\end{array}$ \\
\hline Гордеевский & 12 & 3157 & 84 \\
& 221 \\
\hline Злынковский & 9 & 702 & 155 \\
Клинцовский & 11 & 5510 & 570 \\
\hline Красногорский & 14 & 1052 & 166 \\
\hline Новозыбковский & 12 & 3073 & \multicolumn{2}{|c|}{} \\
\hline
\end{tabular}

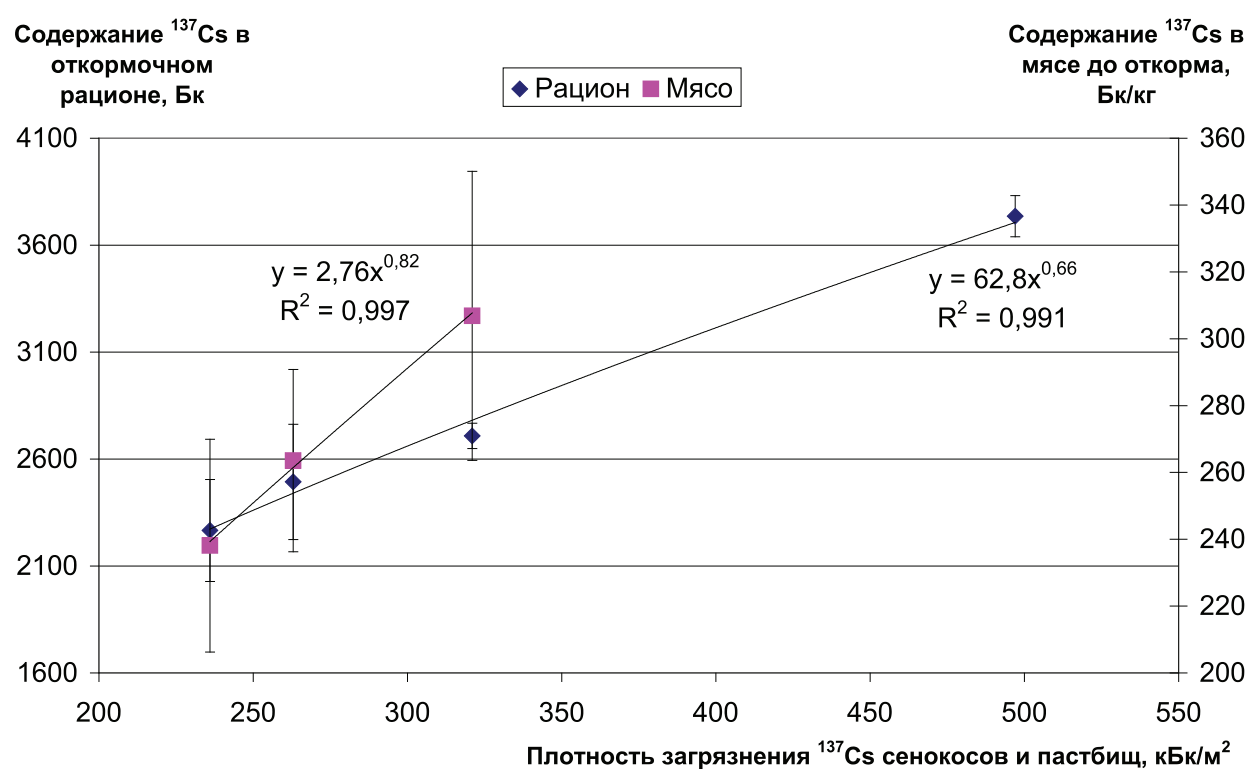

Зависимость содержания ${ }^{137}$ Cs в откормочном рационе и мясе КРС от средневзвешенной плотности радиоактивного загрязнения сенокосов и пастбищ 
Таблица 2

Длительность дополнительного откорма КРС и диапазон безубыточности применения ФСП при различной плотности радиоактивного загрязнения сенокосов и пастбищ

\begin{tabular}{|c|c|c|c|}
\hline $\begin{array}{c}\text { Плотность радиоактивно- } \\
\text { го загрязнения сенокосов } \\
\text { и пастбищ, кБк/м² }\end{array}$ & $\begin{array}{c}\text { Содержание }{ }^{137} \mathrm{Cs} \\
\text { в мясе, Бк/кг }\end{array}$ & $\begin{array}{c}\text { Длительность допол- } \\
\text { нительного откорма, } \\
\text { сутки }\end{array}$ & $\begin{array}{c}\text { Максимальная стоимость } \\
\text { суточной дозы препарата на } \\
\text { голову для положительной } \\
\text { рентабельности, руб. }\end{array}$ \\
\hline 50 & 67 & & 6,16 \\
\hline 100 & 119 & & 12,89 \\
\hline 150 & 165 & & 19,85 \\
\hline 200 & 209 & 5 & 26,96 \\
\hline 250 & 251 & 10 & 34,18 \\
\hline 300 & 292 & 14 & 41,51 \\
\hline 350 & 331 & 18 & 48,91 \\
\hline 400 & 369 & 21 & 56,37 \\
\hline 450 & 406 & 23 & 63,90 \\
\hline 500 & 443 & 26 & 71,49 \\
\hline 550 & 478 & 28 & 79,12 \\
\hline 600 & 514 & 30 & 86,80 \\
\hline 650 & 548 & 32 & 94,51 \\
\hline 700 & 583 & 33 & 102,27 \\
\hline
\end{tabular}

Таблица 3

Стратегия применения ферроцинсодержащих препаратов в зависимости от плотности радиоактивного загрязнения сенокосов и пастбищ

\begin{tabular}{|c|c|c|c|}
\hline $\begin{array}{c}\text { Плотность радиоактив- } \\
\text { ного загрязнения сеноко- } \\
\text { сов и пастбищ, кБк/м² }\end{array}$ & $\begin{array}{c}\text { Применение ферроцинсо- } \\
\text { держащих препаратов }\end{array}$ & $\begin{array}{c}\text { Среднее количество } \\
\text { кормодней на } 1 \text { лактиру- } \\
\text { ющую корову, сутки } \\
\end{array}$ & $\begin{array}{c}\text { Среднее количество } \\
\text { кормодней на } 1 \text { голо- } \\
\text { ву КРС, сутки }\end{array}$ \\
\hline$<150$ & Не требуется & - & - \\
\hline $150-200$ & $\begin{array}{c}\text { Применяется для дойного } \\
\text { стада и КРС на откорме } \\
\text { (кормовые угодья располо- } \\
\text { жены на торфяных и торфо- } \\
\text { глеевых почвах) }\end{array}$ & 88 & 5 \\
\hline $200-300$ & \multirow{3}{*}{$\begin{array}{c}\text { Применяется для дойного } \\
\text { стада и для откорма КРС }\end{array}$} & 126 & 10 \\
\hline $300-500$ & & 160 & 20 \\
\hline$>500$ & & 220 & 30 \\
\hline
\end{tabular}

Потребность в применении ферроцинсодержащих препаратов

Таблица 4 по пяти районам Брянской области

\begin{tabular}{|c|c|c|c|c|}
\hline \multirow[t]{2}{*}{ Район } & \multirow{2}{*}{$\begin{array}{c}\text { Средневзвешенная } \\
\text { плотность радио- } \\
\text { активного загряз- } \\
\text { нения сенокосов } \\
\text { и пастбищ, кБк/м² }\end{array}$} & \multicolumn{2}{|c|}{ Поголовье } & \multirow{2}{*}{$\begin{array}{c}\text { Количество кормодней } \\
\text { применения препарата } \\
\text { для откорма }\end{array}$} \\
\hline & & КРC & коров & \\
\hline Гордеевский & 321 & 6397 & 2939 & 38382 \\
\hline Злынковский & 328 & 1948 & 1035 & 11688 \\
\hline Красногорский & 263 & 4205 & 2370 & 12615 \\
\hline Клинцовский & 236 & 9751 & 3374 & 29253 \\
\hline Новозыбковский & 497 & 5591 & 2477 & 50319 \\
\hline \multicolumn{4}{|l|}{ Итого: } & 142257 \\
\hline
\end{tabular}


Используя полученные закономерности, следует ожидать, что при плотности радиоактивного загрязнения 150 кБк/ $\mathrm{M}^{2}$ среднее содержание ${ }^{137} \mathrm{Cs}$ в мясе КРС составит 165 Бк/кг. Учитывая как погрешность расчетов, так и погрешности измерений радиометрической аппаратуры, можно предположить, что при таком уровне радиоактивного загрязнения сенокосов и пастбищ в хозяйствах может возникнуть необходимость в периодическом применении ферроцинсодержащих препаратов.

Показано, что в зависимости от плотности радиоактивного загрязнения сенокосов и пастбищ будет определяться как продолжительность дополнительного откорма, так и рентабельность применения ФСП (табл. 2).

Исходя из того, что стоимость суточной дозы ФСП (цены 2015 г.) составляла 24 рубля, применение сорбента на заключительной стадии откорма КРС будет рентабельно при плотности радиоактивного загрязнения

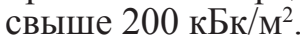

На основании проведенных расчетов можно предложить стратегию применения ферроцинсодержащих препаратов в зависимости от плотности радиоактивного загрязнения сенокосов и пастбищ (табл. 3).

В связи с тем, что ежегодный откорм КРС перед убоем составляет около $30 \%$ от всего поголовья, можно оценить потребность в объемах применения ФСП в условиях радиоактивного загрязнения кормовых угодий, как для различных хозяйств, так и районов в целом (табл. 4).

Следует отметить, что наибольшую потребность в объемах применения ФСП в условиях радиоактивного загрязнения кормовых угодий выявили для хозяйств Новозыбковского района, а наименьшую (в 4,3 раза) для сельхозпредприятий Злынковского района. Определяющими факторами явились плотность загрязнения кормовых угодий и численность продуктивного поголовья скота района.

\section{Заключение}

Таким образом, в результате исследований разработана оптимизированная стратегия применения ферроцинсодержащих препаратов для производства на радиоак- тивно загрязненных территориях Брянской области мяса говядины, соответствующего санитарно-гигиеническим нормативам. Полученные в ходе исследования результаты дают возможность корректировать стратегию реабилитации сферы сельскохозяйственного производства (мясное животноводство) на радиоактивно загрязненных, вследствие аварии на ЧАЭС, территориях.

\section{Список литературы}

1. Алексахин Р.М., Санжарова Н.И. Последствия для сельского хозяйства // Российский национальный доклад «25 лет Чернобыльской аварии. Итоги и перспективы преодоления ее последствий в России. 1986-2011»/ Под ред. С.К. Шойгу и Л.А. Большова. - М., 2011. - С. 38-45.

2. Научные основы реабилитации сельскохозяйственных территорий, загрязненных радиоактивными веществами в результате крупных радиационных аварий. Руководство / Под ред. Н.И. Санжаровой. - ГНУ ВНИИСХРАЭ, 2009. - 150 c.

3. Санжарова Н.И., Фесенко С.В., Романович И.К., Марченко Т.А., Панов А.В., Раздайводин А.Н., Шубина О.А., Прудников П.В., Исамов Н.Н., Радин А.И, Брук Г.Я. Радиологические аспекты возвращения территорий Российской Федерации, пострадавших в результате аварии на Чернобыльской АЭС, к условиям нормальной жизнедеятельности // Радиационная биология. Радиоэкология.-2016.Т. 56, № 3. - С. 322-335.

4. Санитарно-эпидемиологические правила и нормативы СанПиН 2.3.2.2650-10. (Дополнения и изменения № 18 к СанПиН 2.3.2.1078-01). Минздрав РФ, 2010. - 13 с.

5. Титов И.Е., Шубина О.А., Санжарова Н.И., Жигарева Т.Л., Кузнецов В.К. Апробация технологий реабилитации сельскохозяйственных угодий с высокими уровнями радиоактивного загрязнения, временно выведенных из землепользования после аварии на ЧАЭС // Радиация и риск. - 2012. T. 21, № 2. - С. 33-38.

6. Шубина О.А., Титов И.Е., Кречетников В.В., Карпенко Е.И. Краткий обзор результатов паспортизации сельскохозяйственных предприятий на территориях Брянской области, пострадавших после аварии на ЧАЭС// Международный научно-исследовательский журнал. - 2015. - № 11 (42). - Часть 3. - Декабрь. - С. 99-103.

7. Захарова Л.Л., Жоров Г.А., Рубченков П.Н. Ветеринарно-санитарная оценка безопасности кормов и животноводческой продукции на территориях, загрязненных радионуклидами ${ }^{137} \mathrm{Cs}$ и ${ }^{90} \mathrm{Sr} / /$ Проблемы ветеринарной санитарии, гигиены и экологии. - 2013. - № 2(10). - С. 69-72.

8. Исамов Н.Н. (мл.), Цыгвинцев П.Н., Исамов Н.Н., Пишенина Л.В. Эффективность применения ферроцина для снижения содержания ${ }^{137} \mathrm{Cs}$ в молоке и мышечной ткани коров // Вестник Российской академии сельскохозяйственных наук. - 2013. - № 6. - С. 46-48.

9. Ratnikov A.N., Vasiliev A.V., Alexakhin R.M., Krasnova E.G., Pasternak A.D., Howard B.G., Hove K., Strand P. The use of hexacyanoferrates in different forms to reduce radiocaesium contamination of animal products in Russia // Sci. Total Environ. - 1998. - vol. 223. - P. 167-176. 